\title{
Investigating the Impact of Climate Change on Future Runoff of River Satluj
}

\author{
Narayan P. Gautam ${ }^{1 *}$, Manohar Arora ${ }^{2}$, N.K. Goel ${ }^{3}$ and A.R. S. Kumar ${ }^{4}$ \\ 1 Department of Meteorology, Tri-Chandra M. Campus, Tribhuvan University, Kathmandu, Nepal. \\ 2 National Institute of Hydrology, Roorkee 247 667, India \\ 3 Department of Hydrology, IIT Roorkee 247 667, India \\ 4 National Institute of Hydrology, Roorkee 247 667, India
}

\begin{abstract}
Climate change has been emerging as one of the challenges in the global environment. Information of predicted climatic changes in basin scale is highly useful to know the future climatic condition in the basin that ultimately becomes helpful to carry out planning and management of the water resources available in the basin. Climatic scenario is a plausible and often simplified representation of the future climate, based on an internally consistent set of climatological relationships that has been constructed for explicit use in investigating the potential consequences of anthropogenic climate change. This study based on statistical downscaling, provide good example focusing on predicting the rainfall and runoff patterns, using the coarse general circulation model (GCM) outputs. The outputs of the GCMs are utilized to study the impact of climate change on water resources. The present study has been taken up to identify the climate change scenarios for Satluj river basin, India.
\end{abstract}

Keywords: Climate change, climatic scenario, General Circulation Model, statistical downscaling

\section{INTRODUCTION}

Climate is one of the key parameter in the earth's environment. Climate change refers to a change in the state of the climate that can be identified by changes in the mean and/or the variability of its properties and that persists for an extended period, for decades or still longer. The United Nations Framework Convention on Climate Change (UNFCC), in its Article 1, defines climate change as 'a change of climate which is attributed directly or indirectly to human activity that alters the composition of the global atmosphere and which is in addition to natural climate variability observed over comparable time periods' (IPCC, 2008). The average global temperature rose by $0.74^{\circ} \mathrm{C}$ over the last hundred years (1906-2005), with more than half of these rises, $0.44^{\circ} \mathrm{C}$, in the last 25 years (ICIMOD, 2009). Most of the warming over the last 50 years is very likely to have been caused by anthropogenic increases in Green House Gases (GHGs).

Continuous greenhouse gas emissions at or above current rates will cause further warming and induce many changes in the global climate system during the twenty first century that

* Corresponding author : Narayan P. Gautam, Email: ngautam33@gmail.com 
would very likely be larger than those observed during the twentieth century (IPCC, 2007). These changes have the potential to greatly impact regional hydrological processes, and affect long-term water availability ( $\mathrm{Fu}$ et al., 2007), the occurrence of droughts or floods (Bronstert et al., 2007) and water resources management practices (Chiew \& McMahon, 2002), particularly at regional scales (Arnell, 2003). Understanding the potential effects of climate change on hydrological regimes has thus become a priority area, both for process research and for water and catchment management strategies (Jones and Woo, 2002).

Several types of adverse impacts of climate change are seen in various parts of our life. Some of the adverse impacts caused by climate change in global and Asian context can be broadly categorized in the following sections. They are like on water, health, agriculture, forestry, biodiversity, economy, tourism etc. Water distribution is uneven in Asia. It is seen that large areas of Asia are under water stress. On the other hand, Asia has a very high population that is growing at a fast rate, low development levels and weak coping capacity. Climate change is expected to intensify the water scarcity situation in Asia, together with socio-economic stresses (IPCC, 2008).

TheHimalayan regions are located in the northern part of Indian sub-continent. Several types of climatic studies are carried out in the region. The studies have demonstrated significant rise in air temperatures in the Northwest Himalaya of India, Nepal and Tibetan Plateau. Himalayan regions are sources of many rivers as well as it dominantly controls meteorological and hydrological conditions in the Indian subcontinent. It is learned that even a minor change in their climate has a potential to cause disastrous consequences on the socio-economic survival of millions of peoples living in the Indo-Gangetic plains (Bhutiyani et al., 2007).
Most part of the Hindu Kush-Himalayan (HKH) region is situated in the northern part of the Indian sub-continent. It is found that the rate of warming in the $\mathrm{HKH}$ region is higher than global average over the last hundred years. While categorizing the HKH region, as western Himalayas, central Himalayas and Tibetan Plateau, the central Himalayas (Nepal) and the Tibetan Plateau appear to be considerably higher rates of temperature rise (that is, 0.04 to $0.09^{\circ} \mathrm{C}$ per year and 0.03 to $0.07^{\circ} \mathrm{C}$ per year respectively). Future warming scenarios have been generated for the Indian sub-continent using GCMs. It is projected that over the inland regions of the Indian sub-continent, the mean surface temperature may rise between $3.5^{\circ} \mathrm{C}$ and $5.5^{\circ} \mathrm{C}$ by 2080 (Lal, 2001). It has been reported by Lal (2001) that the projected surface warming is higher in winter than during summer monsoon. The spatial pattern of temperature change has a large seasonal dependency. The spatial distribution of surface warming suggests that north India may experience an annual mean surface warming of $3^{\circ} \mathrm{C}$ or more by $2050 \mathrm{~s}$. GCM models have simulated peak warming of $3^{\circ} \mathrm{C}$ over north and central India in winter. Over much of the southern peninsula, the warming is likely to be under $2^{\circ} \mathrm{C}$ during winter season. The surface temperature rise would be more pronounced over northern and eastern region (about $2^{\circ} \mathrm{C}$ ) during the monsoon season. IPCC (2001) has indicated that variability in Asian summer monsoon is expected to increase along with changes in the frequency and intensity of extreme climate events in this region. All climate models simulate an enhanced hydrological cycle and increases in annual mean rainfall over South Asia (under non-aerosol forcing).

In India, limited studies have been conducted by using the statistical downscaling to model stream flow at river basin scale. Tripathi \& Srinivas (2005) have used downscaling of GCMs to access the impact of climate change 
on rainfall of India. A study carried out by (Ghosh \& Mujumdar, 2007) has used statistical downscaling of GCM simulations to stream flow for Mahanadi river basin. Their study has shown the decreasing trend in monsoon stream flow of Mahanadi. Moreover, it can be said that the methodology based on downscaling can be used to model any hydrologic variable such as precipitation, evaporation and so on to access the impact of climate change on hydrology.

\section{Climatic Scenario}

Climate change scenario gives an idea for future state of climate mainly based on anthropogenic climate change. According to the IPCC, a scenario is a coherent, internally consistent and plausible description of a possible future state of the world. A projection may serve as the raw material for a scenario, but scenarios often require additional information (e.g., about baseline conditions). A set of scenarios is often adopted to reflect, the range of uncertainty in projections.

The Special Report on Emissions Scenarios (SRES) were constructed by IPCC in 2000 have been used to explore future developments in the global environment with special reference to the production of greenhouse gases and aerosol precursor emissions. The SRES are categorized in four main families as A1, A2, $\mathrm{B} 1$ and B2. Each scenario represents different demographic, social, economic, technological and environmental developments.

\section{GCM and Downscaling}

The general circulation model (GCM) is also popular by the name of global climate model. GCM represents physical processes in the atmosphere, ocean, cryosphere and land surface. It is the most advanced tool currently available for simulating the response of the global climate system to increasing greenhouse gas concentrations. It has the potential to provide geographically and physically consistent estimates of regional climate change which are required in impact analysis. The atmospheric or oceanic GCMs (AGCM or OGCM) are key components of GCMs which include landsurface, sea-ice and ocean components.

Downscaling is a process of the development of climate data for a point or small area from regional climate information. The regional climate data may originate either from a climate model or from observations. Methodologies to model the hydrologic variables (e.g. precipitation) at a smaller scale based on largescale GCM outputs are known as downscaling. Usually the two downscaling techniques are in practice they are dynamic and statistical downscaling.

Dynamic downscaling uses complex algorithms at a fine grid-scale (typically of the order of 50 $\mathrm{km} \times 50 \mathrm{~km}$ ) describing atmospheric process nested within the GCM outputs. Dynamical downscaling involves the nesting of a higher resolution Regional Climate Model (RCM) within a coarser resolution GCM. It is one of the useful methodologies to carry out study on regional climate change. Better representations of land-use, tropical cyclones, extreme events, orographic precipitation are some of the strong features associated with dynamic downscaling.

Statistical downscaling involves development of statistical relationship between large-scale climate variables and local-scale hydrologic variable. Training (calibration) of the statistical downscaling model requires observed climate data. Statistical downscaling methodologies have several practicaladvantages over dynamical downscaling approaches. From the aspects of low-cost, rapid assessments of localized climate change impacts, statistical downscaling is seen as highly capable technique. 


\section{Importance of the study}

In the past, very few scientific works relating to climate change by General Circulation Model (GCM) have been carried out in South Asian region. Therefore, in present research an attempt has been made for climate change scenario generation by using general circulation model and statistical downscaling technique. This study will be focused to generate the future hydro-climatic scenario near by the Bhakra region of Satluj river basin. Application of statistical downscaling technique on GCM output for future climatic scenario generation is at initial stage in this region. This kind of research has been initiated to fill up the gap existing in between large scale (GCM level) and local scale (basin level) variables.

It is a fact that research on climate change is one of the highly useful methodologies to understand the reality of the climatic condition whether it is at global level or local level. The predicted future hydro-climatic condition will be greatly useful to improve the matters related on planning, decision making systems, etc.

\section{DESCRIPTION OF THE STUDY AREA}

This study has been carried out for Satluj (also spelled as Sutlej) river near by the Bhakra dam within $30^{\circ} 45^{\prime}$ to $33^{\circ} 15^{\prime}$, North latitudes and $76^{0} 10^{\prime}$ to $79^{\circ} 10^{\prime}$ East longitudes (Figure 1). The Satluj River rises from the lakes of Mansarovar and Rakastal in the Tibetan Plateau at an elevation of about $4572 \mathrm{~m}$. It is one of the main tributaries of the Indus River. It is found that about $65 \%$ area of the Satluj river basin has been covered by snow in winter. Considering the snow covered region as well as source of the river, Satluj has been categorized in the Himalayan river system.

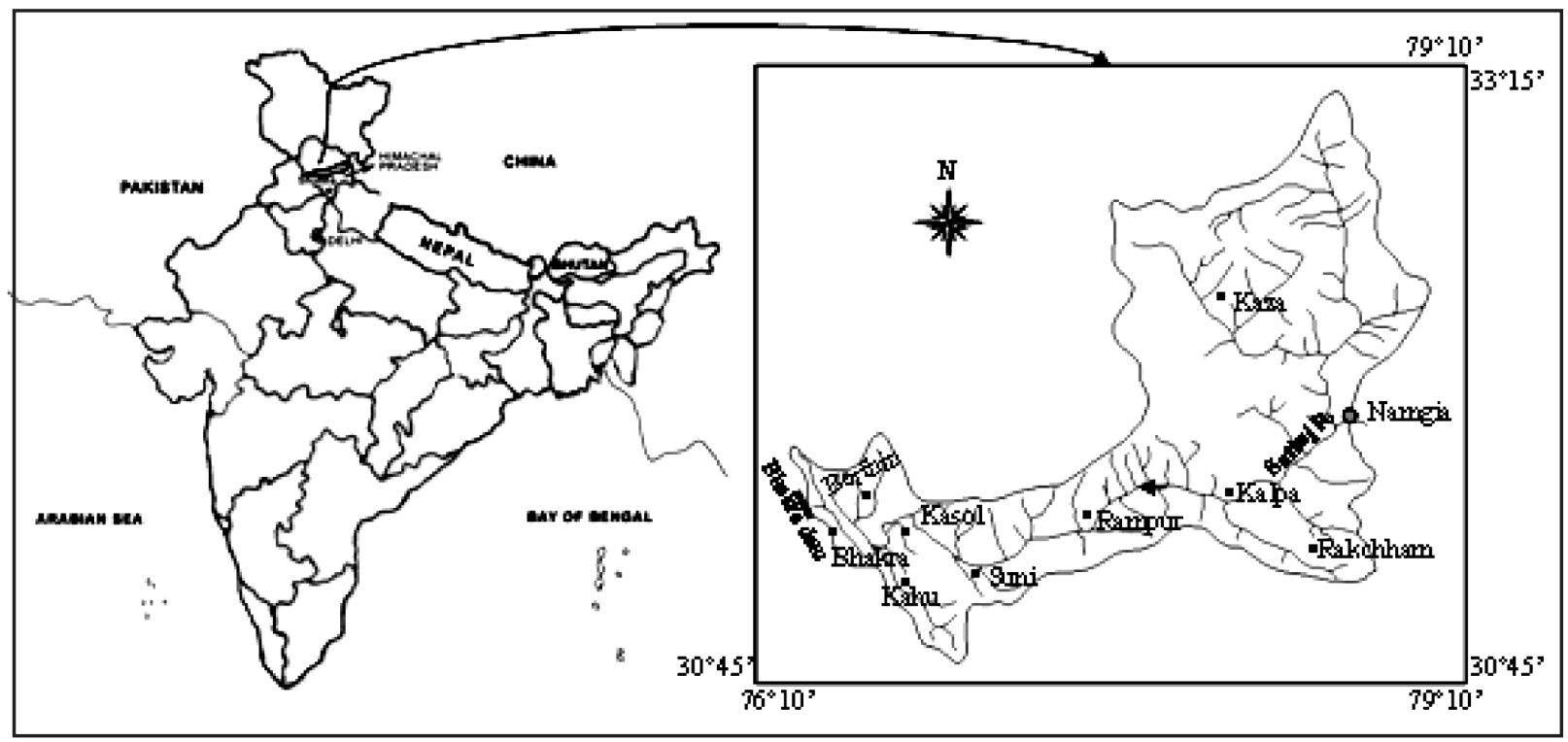

Figure 1: Location map of the Satluj basin up to Bhakra dam with hydrometeorological stations

In India, Himalayan river system that is sustained, at the head, by glacier bearing basins, has been initially classified into three first order basins, 5Q (Indus basin), $5 \mathrm{O}$ (Ganga basin) and $5 \mathrm{P}$ (Brahamputra basin). Satluj river is the longest of the five rivers that flow through the region of Punjab in Northern India and it finally gets merged to Indus in Pakistan. The total catchment area of the River up to the Bhakra dam is about $56,500 \mathrm{~km}^{2}$, of which 
about 22, $305 \mathrm{~km}^{2}$ lies in India (Jain, 2008). The elevation of the catchment varies from 500 to $7000 \mathrm{~m}$ and only a very small area exists above $6000 \mathrm{~m}$. The gradient of the river is very steep at its source and it gradually decreases as it moves downstream. Due to the large differences in seasonal temperatures and the great range of elevation in the catchment area, the snowline is highly variable. The Satluj River receives cool, snowmelt water from the upper basin during the spring and summer months and from monsoon precipitation during July-September in its lower basin. As the river moves down from Khab, Nathpa to Bhakra, contribution from snowmelt decreases and rainfall increases.

\section{DATA USED}

The National Center for Environmental Prediction (NCEP) reanalysis data of the study area have been taken from 1948 to 2004. Data set of wind speed (uwind, vwind), relative humidity, mean sea level pressure, geopotential height and air temperature have been considered to carry out the study. The data have been obtained through the website of NOAA as, http://www.esrl.noaa.gov. In the absence of adequate observed climatological data, the NCEP/ NCAR (National Center for Atmospheric Research) data have been used as a proxy to the observed data.

GCM outputs of CCSR/ NIES Japan have been considered from 2001 to 2100 for projecting future rainfalls. The gridded data sets of mean sea level pressure, specific humidity, wind speed, air temperature have been used as GCM outputs. The gridded data sets of A2 scenario have been used in the study. The GCM data are available in the website of IPCC as, http://www. mad.zmaw.de/IPCC_DDC/html/ddc_gcmdata. $\mathrm{html}$. Mean monthly rainfall of Kasol from 1977 to 2004 have been used as observed rainfall and mean monthly discharge of Kasol and average temperature of Satluj basin from 1987 to 2000 have been considered as observed discharge and temperature data set.

\section{STATISTICAL DOWNSCALING AND TOOLS USED}

Statistical downscaling gives quantitative relationship between large-scale atmospheric variables (predictors) and local surface variables (predictands) (Wilby et al., 2004). Statistical downscaling produces future scenarios based on statistical relationship between large-scale climate features and hydrologic variables like precipitation. One of the most important steps in a downscaling exercise is to select appropriate predictors, or characteristics from GCMs. (Wilby et al., 1999) proposed that there are three main factors constraining the choice of predictors: (1) whether the predictors were reliably simulated by the GCM; (2) how readily available the GCM output data; and (3) the correlation strength with the surface variables of interest. Statistical downscaling methodology can be broadly classified into three categories as weather generators, weather typing and transfer function.

In present study, statistical downscaling has been performed in the following manner. Standardization is performed for both NCEP and GCM output data set. It is applied by the relationship as, $\frac{\text { data-mean }}{\text { standard deviation }}$ Standardization has been carried out to change the scale of measurement of each test variable with a mean of 'zero' and standard deviation of 'one'. Then Principal Component Analysis (PCA) has been taken out for both NCEP and GCM data set using MATLAB. PCA is performed to reduce the dimensionality of the predictor variables. Regression coefficients have been found out with the relationship between NCEP data set and observed rainfall 
and using these regression coefficients to the PCA of GCM output, future rainfall has been predicted.

Easy to use, cheap and readily transferable are some of the strengths and predictor-predictand relationships are often non-stationary, choice of predictor variables affects the results are some of the limitations associated with the statistical downscaling.

Multiple linear regression analysis is used to find the degree of inter-relationship among three or more variables. In present study, multiple linear regression analysis has been used as a tool for analyzing rainfall and rainfall-runoff relationships.

Rainfall variabilty has been conducted to find out the variability in rainfall between observed and predicted rainfall values. In this study, monthly variations of rainfall have been obtained by taking averages of each months of observed and predicted rainfalls based on the average of observed rainfall.

A steady and regular movement in a time series, through which the values are on the average increasing or decreasing, is termed as trend. Trend analysis is one of the important tools to be performed in a hydrologic series. In this study, Mann Kendall test is applied to find out trend in the observed and predicted data set. Artifical Neural Networks (ANNs) are a form of computing inspired by the functioning of the brain and nervous system and are discussed in detail in a number of technical papers published in hydrologic and water resources journals. In present study, ANN has been applied to get rainfall-runoff and rainfall-temperature-runoff relationships (Figure 2).

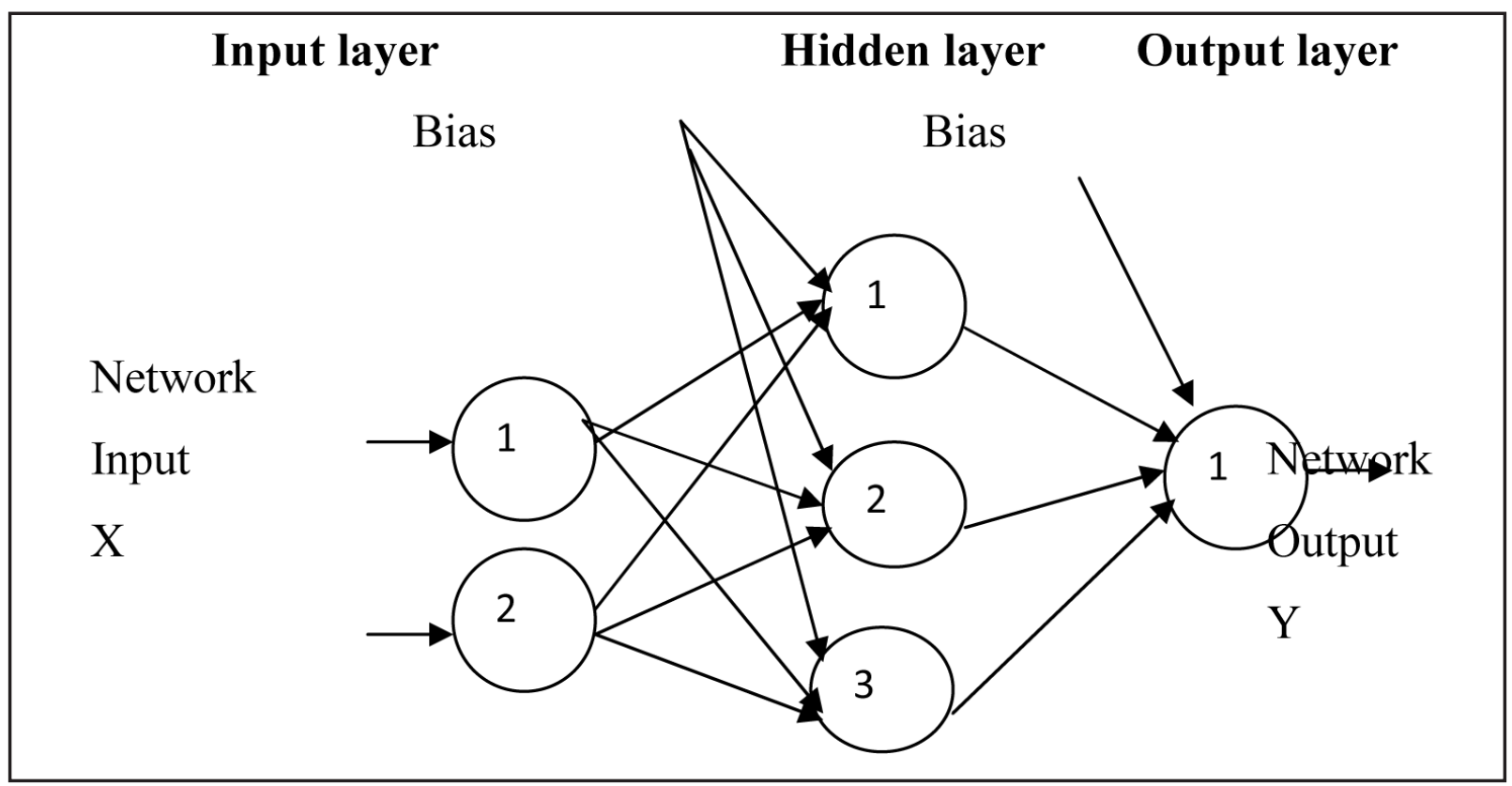

Figure 2: A Typical Three-Layered Feed Forward ANN

\subsection{PERFORMANCE EVALUATION OF ANN MODEL}

The whole data length is divided into three categories based on statistical properties of the time series such as mean and standard deviation, one for calibration (training), another for validation and finally for testing of ANN model. The performance during calibration, validation and testing is evaluated by $\mathrm{p}$ lerformance indices such as root mean square error (RMSE), model 
efficiency (EFF) (Nash and Sutcliffe, 1970) and coefficient of correlation (CORR). They are defined as follows:

Root mean square error $(\mathrm{RMSE})=\sqrt{\frac{\sum_{k=1}^{K}(t-y)^{2}}{K}}$

Efficiency $(\mathrm{EFF})=1-\frac{\sum(t-y)^{2}}{\sum(t-\bar{t})^{2}}$

Coefficient of Correlation $(\mathrm{CORR})=\frac{\sum \boldsymbol{T}}{\sqrt{\sum T^{2} \sum Y^{2}}} \ldots$

where $K$ is the number of observations; $t$ is the observed data; $y$ is computed data; $T=t-\bar{t}$ in which $\bar{t}$ is the mean of the observed data; and $Y=y-\bar{y}$ in which $\bar{y}$ is the mean of the computed data.

\subsection{PREDICTION OF RAINFALL}

Principal component analyses have been carried out from the NCEP data set within the period of 1977 to 2004. In present study, with the application of PCA, $98 \%$ variability was explained by 9 components. Then regression coefficients are obtained with the relationship between PCA of NCEP data and observed rainfalls as given in Table 1.

\section{Table 1: Regression Coefficients}

\begin{tabular}{|c|c|c|c|c|c|c|c|c|c|c|}
\hline Regression Coefficients & $d_{0}$ & $d_{1}$ & $d_{2}$ & $d_{3}$ & $d_{4}$ & $d_{5}$ & $d_{6}$ & $d_{7}$ & $d_{8}$ & $d_{9}$ \\
\hline Values & 109.911 & 17.4775 & -12.0145 & 33.5482 & 7.360 & 4.8876 & -16.618 & -15.2995 & -13.1086 & -31.181 \\
\hline
\end{tabular}

Then using these 9 principal components ( $\mathrm{pci}_{1}$, pci $_{2} \ldots$ pci $\left.{ }_{9}\right)$ and 9 regression coefficients $\left(\mathrm{d}_{0}, \mathrm{~d}_{1}\right.$, $\mathrm{d}_{2} \ldots \mathrm{d}_{9}$ ); rainfall at time $\mathrm{t}$ have been obtained through the equation as:

$$
\text { Rain }_{t}=\mathrm{d}_{0}+\sum_{i=1}^{9} d i * \text { pcit }
$$

The predicted rainfalls have been taken out with the relationship between regression coefficients obtained from NCEP data set and PCA obtained from GCM output. GCM output data analysis has been performed for the data set of A2 scenario. GCM data of 2001 to 2100 have been considered for the study in predicting future rainfall for the next 100 years. Diagrammatic representation of the predicted rainfall values are given in Figures 3 to 6.

Figure 3 has been drawn for the predicted rainfalls from 2001 to 2100 . It is observed from the Figure that for the first 30 years, i.e., from 2001 to 2030 , the maximum monthly rainfalls are above $325 \mathrm{~mm}$ in many years. The same trend is not observed during the remaining

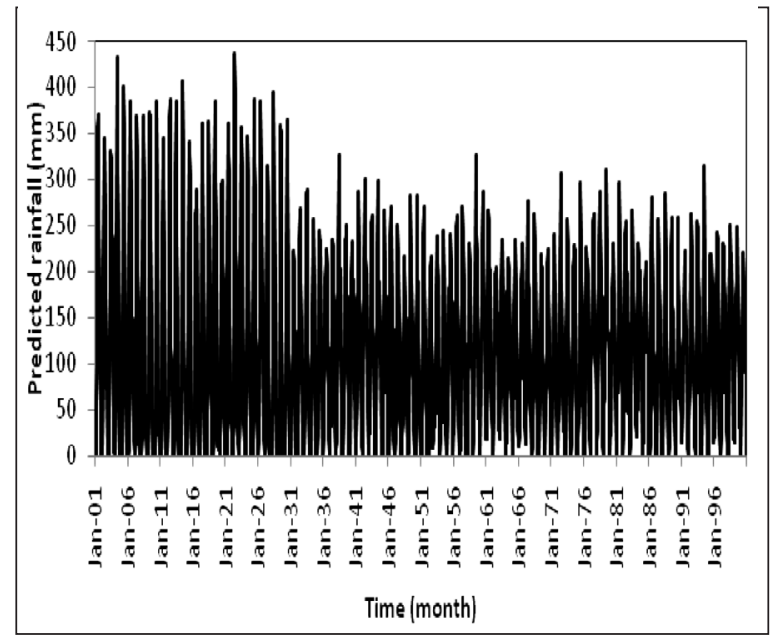

Figure 3: Predicted rainfalls for 2001 to $\mathbf{2 1 0 0}$

period of the prediction. Figures 4 to 6 have been drawn on the predicated monthly rainfalls for the years 2030, 2050 and 2080 respectively. All the Figures have shown that there will be no rainfall in the months of December and January. The amount of rainfall will be very high in June, July and August in compared to the remaining months. Hence, it is finalized that 


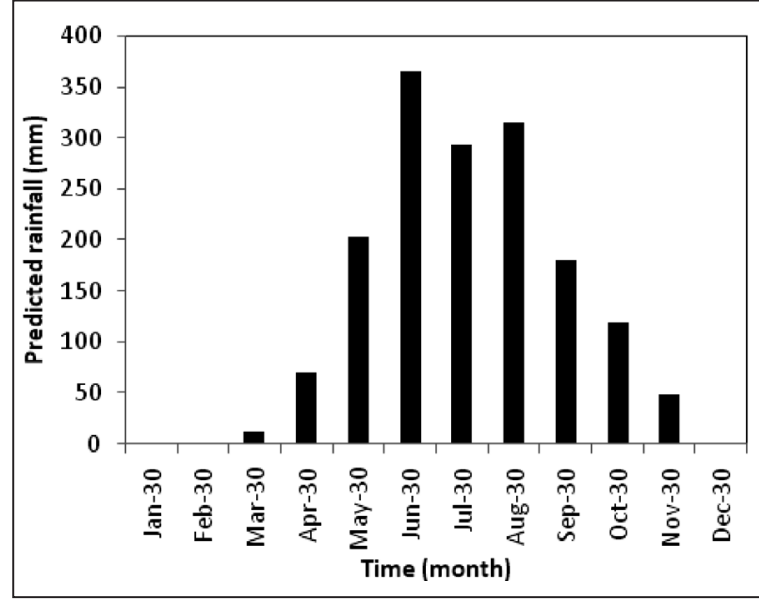

Figure 4: predicted monthly rainfall for 2030

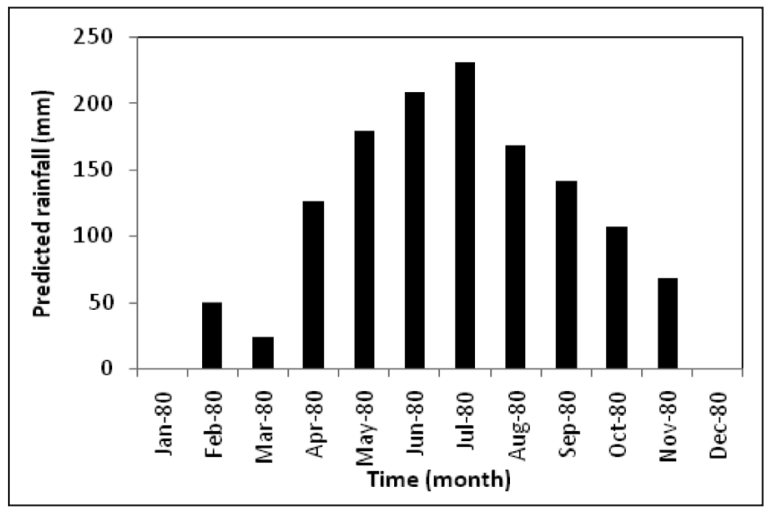

Figure 6: Predicted monthly rainfall for $\mathbf{2 0 8 0}$

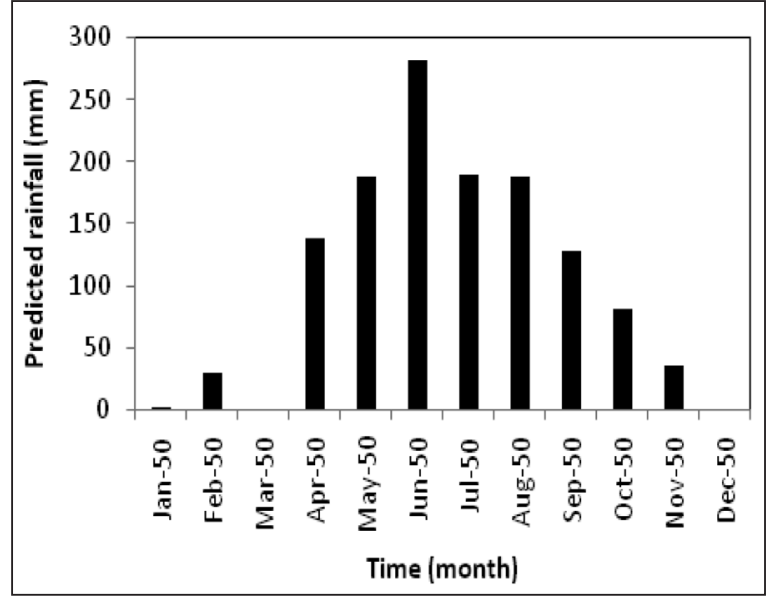

Figure 5: predicted monthly rainfall for $\mathbf{2 0 5 0}$

future rainfalls will highly decrease for winter season in compared to other seasons.

\subsection{RAINFALL VARIABILITY}

Average monthly rainfalls from 1977 to 2004 as well as from 2001 to 2100 have been taken to get rainfall variability within the same month of observed and predicted rainfall data set. The average rainfall values and variations are shown in the Table 2.

Table 2: Rainfall variability obtained from the average rainfall values

\begin{tabular}{|c|c|c|c|}
\hline Month & $\begin{array}{c}\text { Average rainfall from } \\
\text { observed rain data set }(\mathbf{m m})\end{array}$ & $\begin{array}{c}\text { Average rainfall from predicted } \\
\text { rain data set }(\mathbf{m m})\end{array}$ & $\begin{array}{c}\text { Rainfall variation based on } \\
\text { observed rain data set }(\mathbf{\%})\end{array}$ \\
\hline Jan & 59.20 & 5.35 & -90.96 \\
\hline Feb & 55.96 & 17.51 & -68.71 \\
\hline Mar & 62.81 & 38.36 & -38.93 \\
\hline Apr & 38.81 & 89.28 & 130.07 \\
\hline May & 58.17 & 202.13 & 247.48 \\
\hline Jun & 147.95 & 281.61 & 90.34 \\
\hline Jul & 337.79 & 250.08 & -25.97 \\
\hline Aug & 358.36 & 208.19 & -41.91 \\
\hline Sep & 125.92 & 142.98 & 13.55 \\
\hline Oct & 28.52 & 94.26 & 230.54 \\
\hline Nov & 14.86 & 47.98 & 222.94 \\
\hline Dec & 30.60 & 10.95 & -64.21 \\
\hline
\end{tabular}


Diagrammatic representation of the rainfall variability has been given in the Figure 7.

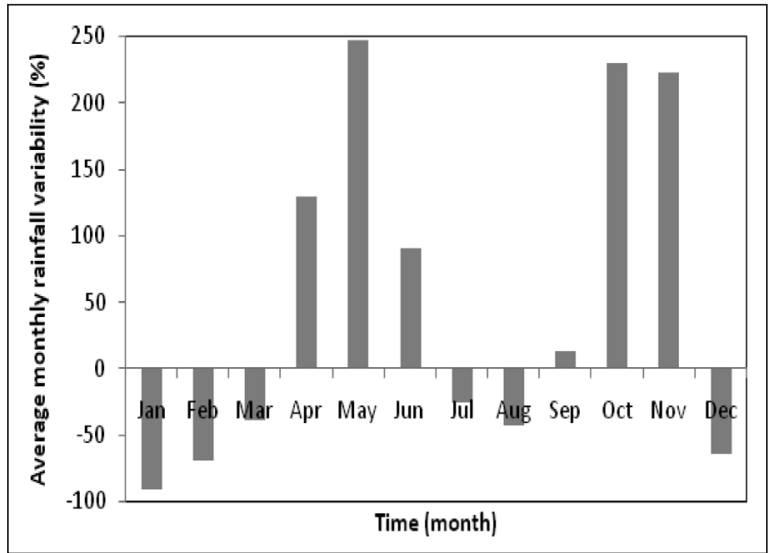

Figure 7: Monthly rainfall variability based on observed rain data set

It is obtained from Figure 8 that there is a condition of positive rainfall variability in the months of April, May, June, September, October and November and there is negative rainfall variability for the months of January, February, March, July, August and December. A scatter plot has been drawn between average observed rainfall and predicted rainfall values. It is given in Figure 8, which shows that lower and medium rainfall values are highly correlated in comparison to the higher values.

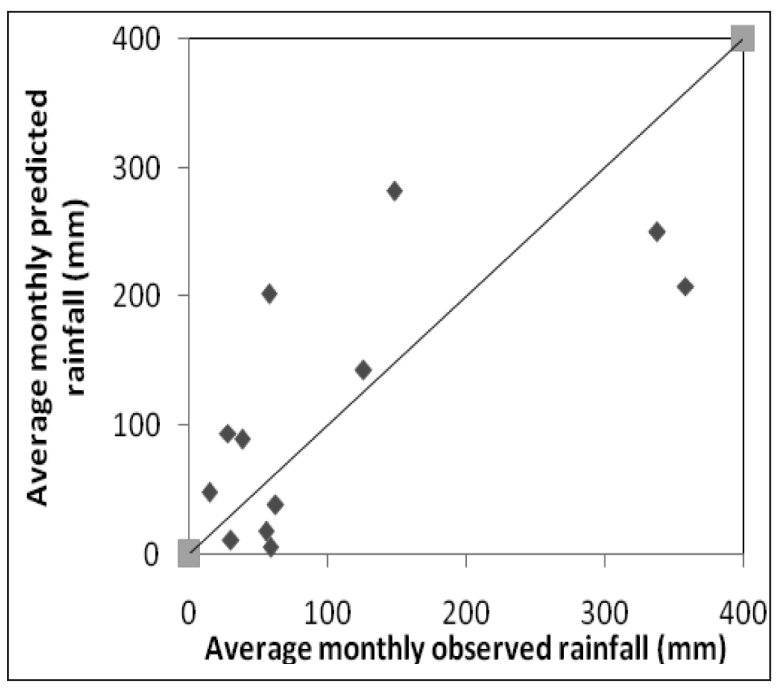

Figure 8: Scatter plot between monthly averages of observed and predicted rainfalls

\subsection{RAINFALL-RUNOFF ANALYSIS WITH DEVELOPMENT OF ANN MODEL}

The ANN models are trained using back propagation algorithm. The whole data set are divided into three sets for the calibration, validation and testing purpose of the ANN model. The data from 1994 to 2000 are considered for the calibration, 1987 to 1990 for validation and 1991 to 1993 testing of the model. The performance of the ANN models during calibration, validation and testing are evaluated with the performance indices mentioned earlier. The correlation coefficient between rainfall and discharge for calibration, validation and testing set data are $0.83,0.74$ and 0.69 respectively. The correlation coefficient between temperature and discharge for calibration, validation and testing set data are $0.83,0.86$ and 0.81 respectively. It clearly indicates that temperature has greater influence on discharge at Kasol.

The results of ANN model with only monthly rainfall as input have been obtained It has given correlation coefficients as $0.87,0.73$ and 0.76; RMSE as 187.04, 270.53 and 248.69 and efficiency as $75.0 \%, 52.0 \%$ and $56.0 \%$ respectively for calibration, validation and testing periods. Similarly, the analysis of ANN model with monthly rainfall and temperature has also been carried out. It has given correlation coefficients as 0.96, 0.96 and 0.92; RMSE as $108.69,133.21$, and 151.51 and efficiency as $92.0 \%, 88.0 \%$ and $83.0 \%$ respectively for calibration, validation and testing periods. Comparing both the results, it can be concluded that input of rainfall and temperature has given better performance than the input of only rainfall.

A Multiple Linear Regression (MLR) models is developed for the prediction of discharge using the monthly rainfall as input vector considered in the development of ANN model. The equation of MLR model is represented by 
$\mathrm{DIS}_{t}=2.25 \mathrm{R}_{t}+164.33$

Where DIS is the monthly average discharge at $t$ and $\mathrm{R}$ is the monthly rainfall at $t$.

Another Multiple Linear Regression (MLR) model is developed for the prediction of discharge using monthly rainfall and monthly average temperature as input vector considered in the development of ANN model. The equation of MLR model is represented by

$\mathrm{DIS}_{t}=1.42 \mathrm{R}_{t}+25.55 \mathrm{~T}_{t}-66.61$

Where DIS is the monthly average discharge at $t$, $\mathrm{T}$ is average monthly temperature at $t$ and $\mathrm{R}$ is the monthly rainfall at $t$.

The performances of best ANN model has been compared with the best MLR model with only monthly rainfall as input. $\mathrm{R}$ for calibration, validation and testing for ANN are $0.87,0.73,0.76$ and $\mathrm{R}$ for MLR model are $0.84,0.74$ and 0.69 respectively. It has shown that performance of ANN model is better than MLR during calibration, validation and testing. Similar type of comparison has been carried out for monthly rainfall and average monthly temperature as input. The inclusion of monthly average temperature in the input improved the performance of ANN and MLR models drastically. $\mathrm{R}$ for calibration, validation and testing for ANN are 0.96, 0.96 and 0.93 and R for MLR model are 0.93, 0.93 and 0.87 respectively. It has clearly shown that the performance of ANN model is better than the performance MLR model during calibration, validation and testing considering monthly rainfall and average monthly temperature as input.

\subsection{SIMULATION OF DISCHARGE FOR FUTURE PERIOD}

The best ANN model is used to simulate the discharge from 2001 to 2100 using future monthly rainfall and average temperature.
Figure 9 represents the simulated discharge for the future period. It is observed from the Figure for the first 30 years, i.e., from 2001 to 2030, the maximum discharges are above 1000 cumecs in many years. The same trend is not observed during the remaining period of the simulation.

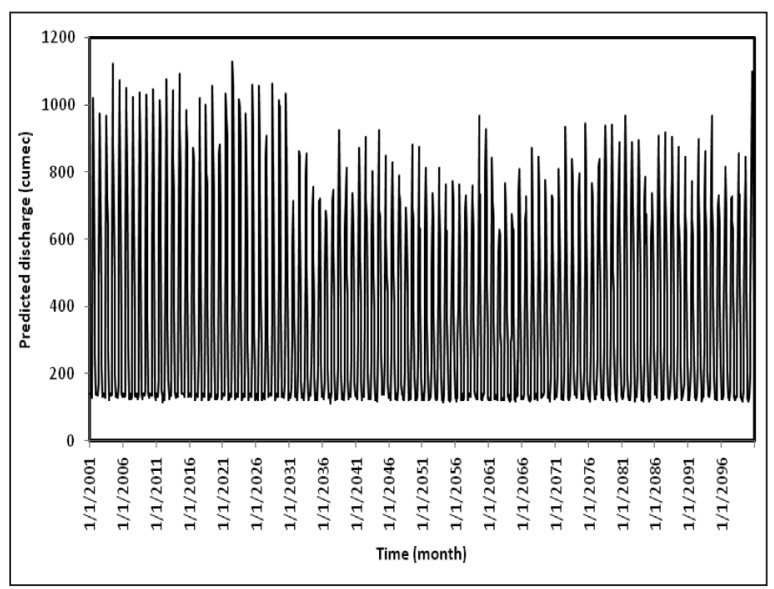

Figure 9: Simulated discharges for future period from 2001 to 2100

\subsection{TREND ANALYSIS OF RAINFALL, DISCHARGE AND TEMPERATURE}

Mann-Kendall test has been applied to identify the trend in the observed and predicted rainfall, discharge and temperature data sets. The test statistics for observed and predicted rainfalls are -0.18 and 0.17 ; discharges are 0.62 and 0.00 and temperatures are 0.99 and 0.48 . All the test statistics have shown that there is no trend in the observed and predicted rainfall, discharge and temperature data set at $5 \%$ significance level.

\section{CONCLUDING REMARKS}

Regression coefficients are obtained by the relationship of NCEP and observed data set and they have been used with GCM output and predicted future rainfall from 2001 to 2100 . It is observed from the future rainfall that the maximum amount of rainfalls are above 325 $\mathrm{mm}$ in many years for the first 30 years and the same trend is not observed during the remaining 
period of the prediction. It is observed from the simulated rainfall of 2030, 2050 and 2080 that the future rainfall will highly decrease for winter season in compared to the remaining prediction periods. Rainfall variability has indicated that rainfall values of December, January and February are on highly decreasing and the rainfalls of May, October and November are on highly increasing order based on the observed data set.

The comparison of the results of the ANN models with MLR for rainfall-discharge and rainfall-temperature-discharge has shown that ANN model is better than MLR model. The predicted discharges for first 30 years from 2001 to 2030 are observed above 1000 cumecs at many months in compared to the remaining prediction periods. The Z-statistics of Mann Kendall test has shown that there is no trend in the observed and predicted rainfalls, discharges and temperatures at $5 \%$ significance level.

Summarizing all, it can be said that prediction of future rainfall and runoff is one of the challenging tasks. Many climatic, hydrologic as well as physical parameters are involved to establish rainfall- runoff relationship in a basin. Furthermore, the results obtained from this study may be crucial in water resources planning and management of Satluj River especially nearby the Bhakra region.

\section{REFERENCES}

Arnell, N.W., 2003. Relative effects of multidecadal climatic variability and changes in the mean and variability of climate due to global warming: future stream flows in Britain. Journal of Hydrology, 270, 195-213.

Bhutiyani, M.R, Kale, V.S. and Pawar, N.J., 2007. Long term trends in maximum, minimum and mean annual air temperatures across the Northwestern Himalaya during the twentieth century. Climatic Change, 85, 159-177.
Bronstert, A, Kolokotronis, V., Schwandt, D. and Straub, H., 2007. Comparison and evaluation of regional climate scenarios for hydrological impact analysis: general scheme and application example. International Journal of Climatology, 27, 1579-1594.

Chiew, F.H.S. and McMahon T.A., 2002. Modelling the impacts of climate change on Australian stream flow. Hydrological Processes, 16, 1235-1245.

Fu, G.B., Charles, S.P. amd Chiew, F.H.S., 2007. A two-parameter climate elasticity of stream flow index to assess climate change effects on annual stream flow. Water Resources. Research, 43, W11419. DOI:10.1029/2007WR005890.

Ghosh, S. \& Mujumdar, P.P., 2007. Statistical downscaling of GCM simulations to stream flow using relevance vector machine. Advances of Water Resources, 31, 132-146.

ICIMOD, 2009. Climate Change in the Himalayas. International Centre for Integrated Mountain Development, Information sheet \#3, Kathmandu, Nepal.

IPCC, 2001. Climate Change 2001: Impacts, Adaptation, and Vulnerability. [McCarthy, J.J., Canziani, O.F., Leary, N.A., Dokken D. J. and avid White K.S. (eds)], Cambridge University Press, Cambridge, UK.

IPCC, 2007. Technical summary, In Climate Change 2007: The Physical Science Basis. Contribution of Working Group I to the Fourth Assessment Report of the Intergovernmental Panel on Climate Change, [Solomon S., Qin D., Manning M., Chen Z., Marquis M., Averyt K. B., Tignor M. and Miller H. L. (eds).], Cambridge University Press: Cambridge and New York; 1-5.

IPCC, 2008. Climate Change and Water. Technical paper of the Intergovernmental Panel on Climate Change [Bates, B.C., Kundzew, Z.W.,Wu, S and Palutikof, J.P.(eds.)], IPCC Secretariat, Geneva. 210pp.

IPCC, 2009. “http://www.mad.zmaw.de/IPCC_ DDC/html/ddc_gcmdata.html.” Accessed 15 November 2009 . 
Jain, S. K., 2008. Development of integrated discharge and sediment rating relation using a Compound Neural Network. J. Hydrol. Engrg., 13(3), 124-131.

Jones, J.A.A. and Woo, M.K., 2002. Modelling the impact of climate change on hydrological regimes. Hydrological Processes 16: 1135.

Lal, M., 2001. Climatic change- Implications for India's water resources. Journal of Indian Water Resources Society, Vol. 21, 101-119.

Nash, J. E. and Sutcliffe, J. V., 1970. River flow forecasting through conceptual models: 1 . a discussion of principles. J. Hydrol., 10(3), 282-290.

NOAA, 2009. http://www.esrl.noaa.gov. Accessed 15 November 2009.
Tripathi, S., Srinivas, V.V. and Nanjundiah, R. S., 2006. Downscaling of precipitation for climate change scenarios: A Support Vector Machine approach. The journal of hydrology, volume 330, issues 3-4, pp 621-640.

Wilby, R.L., Charles, S.P., Zorita E., Timbal B., Whetton, P. and Mearns L.O., 2004. Guidelines for use of Climate Scenarios Developed from Statistical Downscaling Methods. supporting material of the Intergovernmental Panel on Climate Change (IPCC), prepared on behalf of Task Group on Data and Scenario Support for Impacts and Climate Analysis (TGICA).

Wilby, R.L., Hay, L.E., and Leavesley, G.H., 1999. A comparison of downscaled and raw GCM output: a comparison of methods. Water Resources Research, Vol. 34, 2995-3008. 